\title{
A Relação Dialética Turistas/ Moradores em Baependi (Minas Gerais): Percepções Diferentes Sobre a Mesma Produção Socioespacial
}

https://doi.org/10.21814/uminho.ed.48.19

\author{
Magno Angelo Kelmer \\ Universidade Federal de Goiás, Goiás, Brasil \\ https://orcid.org/0000-0003-4905-4889 \\ magnokelmer@gmail.com
}

Annaelise Fritz Machado

Escola Superior de Hotelaria e Turismo, Instituto Politécnico do Cávado e do Ave, Barcelos, Portugal https://orcid.org/0000-0003-3849-7350 annaelisefritz@yahoo.com.br

\section{Resumo}

O município de Baependi, no sul do estado de Minas Gerais, conta atualmente com a presença da atividade turística do tipo religioso, na qual visitantes buscam conhecer os atrativos do local onde Nhá Chica viveu. Nhá Chica foi uma neta de escravos africanos, da região de Benguela, que, nascida no Brasil, escolheu o município de Baependi para viver. Segundo relatos, essa beata possuía dons relacionados a benzeções e adivinhações. Após sua morte, a beata passou a ser venerada e, em 2013, sua beatificação foi realizada. Com isso, um número crescente de turistas quer conhecer mais sobre Nhá Chica, fazendo com que Baependi tenha um maior fluxo de visitação envolvendo a fé, caracterizando a prática do turismo religioso, fato que tem contribuído para a sua reprodução socioespacial. Desta forma o município passou a se organizar para receber e explorar essa atividade econômica, o que mereceu uma análise sobre tal organização. Para isso, visitas a campo com entrevistas direcionadas ao visitante e ao morador foram realizadas. Este trabalho, ao analisar as transformações do espaço na visão do morador de Baependi e do turista que ali chega, busca compreender o processo de reprodução do espaço, no qual está contida a organização espacial, já que a lógica do capital impõe uma racionalidade na organização do espaço, programando-o para a mercantilização e o consumo, valorizando a relação dialética valor de uso-valor de troca, fornecendo novo sentido para os espaços. 


\section{Palavras-chave}

turismo religioso, produção do espaço, turistas, moradores

\section{Introdução}

Nhá Chica, batizada como Francisca de Paula de Jesus, nascida em 1808, ficou órfã muito cedo e dedicou sua vida a praticar a caridade e conservar a fé cristã. Sua fama de santidade foi se espalhando de tal modo que visitantes vinham a Baependi para conhecê-la e pedir-lhe orações. Com sua morte, em 1895, a memória sobre essa personagem não foi perdida, ao contrário, seus restos mortais, no interior da Igreja de Nossa Senhora da Conceição, vêm sendo visitados e venerados por fiéis brasileiros e estrangeiros. A sua beatificação, ocorrida em maio de 2013 na cidade de Baependi, no estado de Minas Gerais, veio ao encontro dos anseios de uma comunidade que acompanha há décadas as manifestações atribuídas a ela.

O município de Baependi, localizado no sul do Estado de Minas Gerais, possui, segundo dados do Instituto Brasileiro de Geografia e Estatística (IBGE, s.d.), uma população de 18.307 habitantes e a atividade turística tem-se tornado um forte movimentador de capital em uma economia local, movida até então pela agropecuária e pelo comércio.

A beatificação faz parte de um processo de canonização instaurado em janeiro de 1992; processo este que aumentou a divulgação dos supostos milagres atribuídos à beata, implicando um maior fluxo de visitação envolvendo a fé e caracterizando a prática do turismo religioso, fato que tem contribuído para a reprodução socioespacial do município.

O turismo, na qualidade de atividade sócio-econômica, tem o poder de modificar os espaços, transformando-os para e pela sua atuação, relacionando elementos administrativos, econômicos, culturais, naturais e principalmente os elementos sociais, demonstrando assim a dinamicidade da atividade.

Diante deste cenário, questiona-se a importância desse atrativo para a economia do município e para a relação entre moradores e visitantes. A atividade turística apresenta aspectos positivos, destacados para justificar sua atuação, e negativos que negam os discursos enaltecedores sobre a atividade. $O$ fato de haver maior visitação no município estabelece uma relação dialética entre moradores e visitantes, o que merece ser investigado. 


\section{Nhá Chica: A Semente de Benguela Santificada Para o Turismo}

Roza de Benguela chegou ao Brasil por um navio negreiro e foi comprada pelo fazendeiro Custódio Ferreira Braga, da zona rural de São João Del-Rey, em Minas Gerais, dando a luz, na década de 1780, Izabel. Ao longo de sua vida, Izabel teve dois filhos, Theotônio Pereira do Amaral e Francisca de Paula de Jesus, nascida em 1808. Segundo Palazzolo (1973), "dona Izabel, mãe de Francisca de Paula de Jesus, possuía sólida formação cristã, era conhecedora das vantagens de uma vida em retiro, quase monástica" (p. 18), o que foi passado à filha como formação, orientando-a para uma vida de servidão a Deus. Izabel, já liberta, resolve se mudar com a família para Baependi, sul do estado de Minas Gerais, levando seus dois filhos e a imagem de Nossa Senhora da Conceição, sua santa de devoção. Ao chegar a Baependi, a família se instalou em uma casa na rua das Cavalhadas (Lefort, 1992). Em 1818, Izabel morre deixando órfãos seus dois filhos. Após a morte da mãe, Francisca de Paula passou a viver sob votos de pobreza, mantendo-se solitária para melhor praticar a caridade e o cristianismo (“História", s.d.).

Seda (2013) nos esclarece quanto ao dinamismo de Francisca, ao afirmar que, em sua participação na missa ou em seu caminhar tranquilo pelas ruas de Baependi, levava comida aos mais necessitados, remédios caseiros aos doentes, sempre pronunciando uma oração, distribuindo graça e bondade... Tinha Francisca como nome de batismo, mas o povo simples começou a chamá-la de Nhá Chica.

Sua fama de santidade foi se espalhando e pessoas de outras localidades começaram a visitar Baependi para conhecê-la, conversar com ela, falar-lhes de suas dores e necessidades e, sobretudo, para pedir-lhe orações. Baseado nos relatos de Sacramento (2006), "Nhá Chica faleceu em 14 de junho de 1895 em consequência de anemia geral por causa de afecções gástricas" (p.161). Após sua morte, a fama da "santinha de Baependi" se espalhou e possíveis milagres começaram a ser atribuídos a ela. A capela iniciada em 1867 por Francisca de Paula de Jesus, atualmente reformada e transformada em santuário, recebe anualmente a visita de milhares de fiéis.

Visitantes são atraídos a Baependi para conhecer a igreja de Nhá Chica, onde se encontram seus restos mortais depositados em uma urna sob sua estátua, localizados à esquerda do altar do Santuário de Nossa Senhora da Conceição. Com isso, um número crescente de visitantes quer conhecer mais sobre Nhá Chica, fazendo com que o município de Baependi tenha um maior fluxo de visitação envolvendo a fé, caracterizando a prática do turismo religioso, fato que tem contribuído para a sua reprodução socioespacial. Andrade (2000) conceitua turismo religioso como "o conjunto de atividades, com utilização parcial ou total de equipamentos e a realização de visitas a receptivos que expressam sentimentos místicos ou suscitam a fé, a esperança e a caridade aos crentes ou pessoas vinculadas a religiões" (p. 77).

A importância dada aos equipamentos para o suporte da visitação turística é destacada pelo autor e, desta forma, surge uma nova produção socioespacial que merece 
ser analisada, pensada e discutida juntamente com a força que a modificou, uma vez que a lógica do capital nos impõem uma racionalidade na organização do espaço, programando-o para a mercantilização e o consumo em uma relação dialética entre valor de uso-valor de troca. Lefebvre (1972/2008) contribui ao destacar que o "ordenamento do espaço se dá segundo as exigências do modo de produção capitalista, ou seja, da reprodução das relações de produção" (p. 21); em Baependi, a atividade turística classificada como turismo religioso contribui para isto, apresentando-se como uma entre as demais atividades presentes contribuindo para seu processo de reprodução espacial.

Em 1992, o processo de beatificação foi aberto de forma definitiva culminando na beatificação a 4 de maio de 2013. Analisando o recorte temporal entre 1992 a 2016, conforme os dados da prefeitura municipal, a economia do município sofreu alterações referentes à quantidade de alvarás liberados para atividades do setor terciário da economia, que tiveram um acréscimo de $252,3 \%$, sendo este o setor que abrange as atividades ligadas à prática do turismo; destacando entre eles, os cinco hotéis que foram inaugurados em Baependi nos últimos 15 anos, indicando desta forma, um aumento no fluxo de visitantes. Segundo dados do IBGE (2010), em Baependi, na década atual (2010 a 2016), a população economicamente ativa no setor terciário teve um acréscimo de $2,81 \%$, ou seja, aumentou o número de trabalhadores envolvidos no setor que abrange as atividades das práticas turísticas, fato que pode interferir na distribuição da população no município, uma vez que, a taxa de urbanização saltou de $62,51 \%$ em 1990 para 72,4\% em 2010. Neste período a população do município cresceu 10,1\%.

Vários agentes atuam em Baependi, contribuindo para a dinamização da atividade turística, promovendo a turistificação dos lugares.

\section{Turistificando o Espaço: Moradores e Turistas}

Os agentes envolvidos no processo de turistificação contribuem para a produção da atividade turística e, concomitantemente, para a produção do espaço. As ações por eles implementadas impactam o espaço, contribuindo para a tríade dialética, prática espacial, representação do espaço e espaço da representação. Lefebvre (1972/2008) aponta os conceitos estabelecidos como espaço concebido, planejado, uma relação entre os dominantes e o produto. Esta relação resultará no espaço do vivido, do cotidiano, do ir e vir das pessoas, habitantes e usuários deste espaço. Permeando estas relações e, como resultado delas, o espaço do percebido nos remete para a materialidade desta produção enquanto prática espacial concluindo assim a tríade dialética do autor.

Os moradores transitam entre estes espaços contribuindo para o seu processo de produção, uma vez que dele usufruem e modificam-no. Estes sujeitos contêm a experiência do cotidiano, das relações diárias e necessitam ser interpretados em suas relações econômicas, políticas e culturais (Gottdiener, 1993/2010; Lefebvre, 2000/2006).

Os moradores entrevistados são residentes do bairro Centro, por ser o bairro a receber maior circulação de visitantes e conter o maior número de atrativos turísticos 
religiosos de Baependi. Foram entrevistados 45 moradores, envolvendo um universo de 150 pessoas na pesquisa ao contar com o número total que compõe cada família. O grupo dos entrevistados é composto por $80 \%$ de moradores católicos e de $20 \%$ de moradores não católicos e organizamos, para atender ao recorte temporal estabelecido para este trabalho, moradores do bairro antes do início do processo de beatificação em 1992, representando $53,3 \%$ do total, e moradores do bairro após a data de início do processo de beatificação, representando 46,7\%, uma vez que esta informação ajudará a comparar os dados antes e após o processo de beatificação.

Para $97,9 \%$ dos visitantes entrevistados, os moradores recebem bem o turista, destacando como qualidades da população residente o fato de ajudarem com informações, serem receptivos e simpáticos, demonstrando estarem satisfeitos com a presença do turista, afinal para a maioria dos entrevistados, a hospitalidade dos moradores foi citada. Para 2,1\% dos visitantes, os moradores não são receptivos e, para estes, os moradores não veem com "bons olhos" o/a turista.

Independentemente de gostar ou não da presença do visitante na cidade, o morador participa no processo de turistificação, não de forma homogênea, uma vez que com a prática da atividade turística uns irão ganhar, seja financeiramente, seja pelo uso das estruturas montadas para o visitante, seja pela troca cultural estabelecida, e outros não; estes veem-se prejudicados pela presença do visitante. Mas o fato importante nesta análise diz respeito à presença do morador no cotidiano, vivenciando sua experiência como habitante e as relações com os usuários do espaço. $O$ habitante, para Lefebvre (1972/2008), tem importância fundamental na análise dos espaços, não somente em dados quantitativos mas, como o elemento que atua na prática urbana, representando a qualidade da produção espacial.

Os moradores de Baependi, em sua maioria, $66,7 \%$ do total de entrevistados, sentem-se envolvidos com a prática turística citando como exemplo o fato de orientar o visitante, atuar nas celebrações da igreja e ganhar financeiramente com o comércio, principalmente o relacionado a Nhá Chica. Destes entrevistados, $26,7 \%$ sentem-se alienados das práticas turísticas e 6,6\% não souberam responder a esta questão.

Andrade (2000) deixa claro a importância da receptividade dos moradores para o turista ao afirmar que os viajantes, os hóspedes, os clientes, "sempre que se julgam na situação de turistas, desejam sentir-se entre amigos e camaradas, na mesma proporção da sinceridade, da segurança e do conforto que desejariam possuir em suas casas, a fim de descansar, de distrair-se e de relaxar" (p. 26), demonstrando assim, o papel dos moradores no processo de turistificação.

Todos os moradores que foram entrevistados afirmaram perceber a movimentação turística na cidade e apontam o turismo religioso (93,3\%), tendo como atrativo Nhá Chica e a fé, e o turismo de aventura (6,7\%), citando as cachoeiras da cidade, como os tipos de turismo praticados no município. 
Figura 1

Modificações ocorridas com a presença da atividade turística. Fonte. Kelmer (2015/2016).

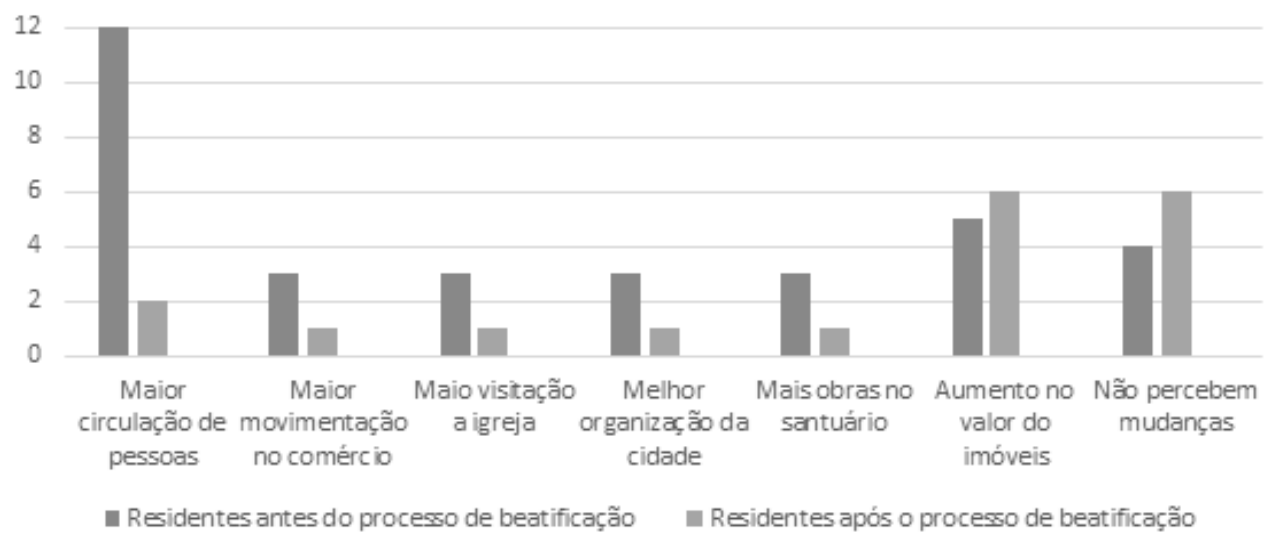

Este gráfico estabelece uma relação entre os entrevistados que já moravam no centro antes do início do processo de beatificação de Nhá Chica, em 1992, e os que passaram a morar no bairro após esta data e apontam modificações citadas por eles. Para os moradores mais antigos, as mudanças dizem respeito a maior circulação de pessoas no bairro, principalmente aos finais de semana; maior movimentação no comércio; mais pessoas visitando a igreja de Nhá Chica; a melhor organização da cidade e as obras do santuário, para criação do centro de recepção dos romeiros. Estes itens, na percepção dos moradores mais recentes, não tiveram uma representação significativa, uma vez que, para eles, o bairro sempre teve estes movimentos citados, não significando mudanças. 0 item citado como maior mudança, inclusive gerando muitas reclamações, diz respeito ao aumento do valor dos imóveis, seja para compra ou para o aluguel.

Os moradores entrevistados não demonstraram resistências especificamente ao turismo, mas alguns moradores $(13,3 \%)$ posicionaram-se contra certos praticantes do turismo religioso que causam problemas, como barulho, lixo, embriaguez e transtorno no trânsito das ruas do bairro.

Ao entender os turistas como um conjunto complexo, instável e contraditório de pessoas temporariamente fora de seu local de origem visitando o mesmo lugar, nota-se interesses diferentes quanto ao uso do espaço em questão, apropriando-se dele, apresentando interesses diversos e até contrários aos da maioria, caracterizando um grupo com interesses diferentes como pode ser observado em Baependi. Durante as idas a campo, foram identificados grupos de visitantes que não frequentavam o santuário e não consumiam produtos relacionados com a beata; o interesse estava nos bares e restaurantes do entorno do santuário. É justamente este turista que é referido como incomodando o morador.

Para Souza (2002), a população das áreas de destino dos turistas pode ganhar ou perder, dependendo do modo como o turismo ocorre nessas áreas. Os moradores, em Baependi, reclamam da organização do turismo no município, justamente por não serem incluídos no planejamento, não causando mudanças no seu dia a dia; opinião 
compartilhada por $60 \%$ dos entrevistados, que apontam a prefeitura como culpada ao não incluí-los nas discussões sobre os assuntos relativos a prática do turismo e, principalmente, ao bairro no qual residem.

Para haver maior valorização do turismo pelos moradores é necessário haver maior envolvimento dos mesmos no processo, passando pela valorização da troca de culturas, ganhos em conhecimento e a obtenção de lucro com a atividade. Somente $6,7 \%$ dos entrevistados possuem familiares obtendo renda com o turismo religioso em Baependi.

A oferta turística é planejada para atender aos visitantes, criando elementos como mercadorias que serão consumidas na atividade turística, reproduzindo assim o espaço geográfico. Desta forma, as transformações ocorridas no espaço de Baependi buscam atender, também, de maneira direcionada a este visitante, entendido como um agente de turistificação, representado na figura do turista ${ }^{1}$. Para Knafou (2001), o turista está na origem do turismo, ao estabelecer que não são os produtos e sim as práticas que dão origem ao processo, sendo eles fundamentais na criação dos lugares turísticos. Cruz (2003) destaca que os "diversos lugares foram e ainda são inventados como lugares turísticos em função da prática espontânea de certos turistas” (p. 14).

O turista é um agente de fundamental importância no processo de turistificação dos espaços, já que ao vivencia-los irá elaborar seus conceitos e acabará definindo quais partes do espaço serão turísticas. Knafou (2001) destaca que não existem lugares turísticos sem turistas, consequentemente, os processos de turistificação dos espaços passam pela avaliação subjetiva que motiva o turista a eleger um destino.

Baseado em trabalho de campo realizado em Baependi ao longo dos anos de 2015 e 2016, em dias de maior e menor movimentação turística, constatou-se que $82,3 \%$ dos 96 visitantes entrevistados apresentam gastos com alimentação, 28,1\% com lembranças, $8,4 \%$ com artesanato e $1 \%$ com passeios pela cidade, contribuindo financeiramente para a economia do município por meio das atividades turísticas. Importante destacar que, na entrevista, os visitantes apontaram mais de um item de consumo. Com relação aos valores gastos, estipulamos gastos até 50R $\$$, representando $58,3 \%$ dos entrevistados, e gastos acima de $50 \mathrm{R} \$$, representando $41,7 \%$ do total.

Quanto à organização das estruturas para receber o turista, $66,7 \%$ dos entrevistados responderam "sim" à pergunta: "a estrutura de Baependi - MG correspondeu a sua expectativa?". Para esta mesma pergunta, obteve-se $20,8 \%$ de "não" como resposta e $12,5 \%$ não souberam responder. Caldeira (2014) chama-nos a atenção justamente para a importância de se estruturar bem os espaços turísticos para receber o turista, uma vez que, segundo o autor,

o turismo organizado deve oferecer atendimento especial, que inclui informações sobre os lugares, itinerários, guias, acomodações, transporte e outras

10 termo "turista" é passível de reformulações por abrigar um grupo heterogêneo de pessoas com características, personalidades, demografias e experiências diferentes (Cooper et al., 1998/2001) e será entendido, neste momento, como um visitante fora de seu local de origem por motivos diversos. 
provisões que facilitem e produzam resultado em cadeia, já que o turista irá repassar informações a outras pessoas, provavelmente turistas em potencial. (p. 147)

Com relação à questão citada, os entrevistados apontaram a sinalização da cidade, a organização no entorno do santuário, a estrutura de Baependi e, principalmente a hospitalidade do morador como elementos positivos da estrutura do lugar. Já para os entrevistados que não tiveram suas expectativas correspondidas, a falta de estrutura como banheiros públicos, lanchonetes, acomodações para o turista e estacionamento para automóveis foram os itens mais citados como negativos. Interessante destacar que $100 \%$ dos entrevistados recomendariam o passeio a um amigo.

Durante trabalho de campo, entrevistámos visitantes de três estados brasileiros: Minas Gerais, São Paulo e Rio de Janeiro, representando 66,7\%; 28,1\% e 5,2\% respectivamente. Os visitantes que tomaram conhecimento de Nhá Chica por intermédio da família totalizam $35,4 \%$ do total, informação pelos amigos com $18,8 \%$, informação pela televisão com $14,6 \%$ e por informações pela igreja com $10,4 \%$. Os visitantes que tomaram conhecimento pela excursão e os que somente tomaram conhecimento no local totalizam $6,2 \%$ cada. Já os visitantes que souberam de Nhá Chica pela divulgação do processo de beatificação e pela internet totalizaram $4,2 \%$ cada. Conclui-se que, independentemente do local de origem, as maneiras como os visitantes tomaram conhecimento sobre Nhá Chica são diversas e que as associadas ao "boca a boca" são as mais representadas, constatando assim o papel do turista no processo de turistificação.

Os turistas, segundo Knafou (2001), estão na base do processo de turistificação dos lugares. No entender do autor, não somente o turista enquanto sujeito, mas suas práticas sociais envolvendo deslocamentos temporários fazendo surgir os espaços turísticos. Assim, o turista na busca de novos ares, diferentes do seu dia a dia, se apropria de alguns espaços, contribuindo para o seu processo de reprodução. 0 turista participa dos espaços da representação ao experimentar da prática cotidiana dos lugares. Este espaço é entendido por Lefebvre (2000/2006) como o espaço do vivido, no qual, através das imagens e símbolos que o compõem, os "usadores" o acompanham.

Os usadores para Lefebvre (1972/2008) compõem um grupo particular que se apropria do espaço para explorá-lo, utilizando os seus recursos, contribuindo e reafirmando a relação dialética valor de uso e valor de troca. Assim, ao associar o termo "usadores" ao papel dos turistas como agente de turistificação, atribui-se a eles um papel fundamental na produção do espaço.

Quando perguntados sobre os pontos positivos de Baependi, 23,9\% dos entrevistados apontaram a receptividade do povo, seguidos por $15,6 \%$ que assinalam a igreja de Nhá Chica juntamente com a fé presente no local, com a mesma proporção de opiniões. Nhá Chica foi citada por 10,4\% dos entrevistados, a estrutura da cidade foi citada por $7,5 \%$ e com a mesma proporção de $4,2 \%$ os itens: tranquilidade, religiosidade e a cidade. Com $1 \%$ de participação neste item da entrevista, surgiram os passeios no município, cachoeiras, feirinha e "tudo" na cidade. Os que não sabiam responder a esta questão, totalizaram $10,4 \%$. 
Na mesma questão foram solicitados os pontos negativos em Baependi e para 47,9\% dos entrevistados "nada" na cidade configura-se como negativo. A estrutura da cidade apareceu em seguida com $16,7 \%$, a organização para receber o turista com $5,2 \%$, a falta de hotéis e a falta de locais para alimentação representam $4,2 \%$ cada. 0 tamanho da igreja e a falta de variedade no comércio representam 3,1\% cada e, para 2,1\% do total, a falta de restaurantes é um problema. Os que não sabiam responder a esta questão e os que não gostaram da feirinha representam $12,5 \%$ e $1,0 \%$ respectivamente.

Os turistas, no entender de Cruz (2007), exercem papel fundamental no processo de turistificação, uma vez que eles foram responsáveis, ao longo da história, pela invenção de muitos destinos turísticos e por deflagrarem novas dinâmicas nos processos de produção do espaço dos quais se apropriaram. Assim, as práticas sociais em forma de deslocamentos temporários fazem surgir os espaços turísticos. 0 turista atua na busca de novas paisagens, diferentes do seu cotidiano, apropriando-se de outros espaços com características endêmicas, entre elas, os aspectos religiosos.

A beatificação de Nhá Chica atende, em primeiro plano, às questões religiosas e, pautado no apresentado até aqui, ao papel do turista, como um entre os outros agentes da turistificação que contribui na criação da demanda ao eleger Baependi como um destino de turismo religioso.

Entender somente o indivíduo como agente do turismo, com suas necessidades e desejos subjetivos, além de estabelecer uma relação simplista, implica uma relação cartesiana de sujeito e objeto longe de atender as análises do turismo enquanto atividade transformadora dos espaços. Desta forma, Fratucci (2007) colabora ao compreender o turismo como

um conjunto de agentes/elementos, inter-relacionados no tempo e no espaço, que compõe uma rede territorial e de relacionamentos, sazonal, flexível e fluída, onde ocorrem os encontros de alteridades distintas (do turista, do trabalhador, do anfitrião, do poder público e do capital), apoiadas tanto pela lógica da produção como da do consumo. (p. 3)

Para uma análise mais fidedigna possível, precisamos elencar uma variedade de agentes que se inter-relacionam para o acontecer turístico: os representantes do capital, portanto do mercado, tratados como trade turístico; o poder público, em seus diversos níveis; as comunidades das áreas receptoras; os planejadores territoriais do turismo; e, também, o turista, como já trabalhado.

A igreja católica participa, de forma indireta, no processo de promoção do turismo religioso ao divulgar a beata. Classificamos como indireta a participação da igreja católica, como um agente de turistificação, pelo fato de não haver um tratamento claro com relação ao turismo e aos turistas, tratando-os como peregrinos, devotos ou romeiros. Como constatado in loco, durante as celebrações da missa aos domingos e em dias de festas religiosas, ocorre a presença de um animador antes da celebração. Este acolhe os visitantes e incentiva-os a registrarem suas romarias na Associação Beneficente Nhá Chica (ABNC); estimula também as pessoas a registrarem as graças 
alcançadas, por intermédio de Nhá Chica, no livro de registros da igreja. Esta atividade é realizada também por uma freira da $A B N C$ responsável por organizar as missas.

Entre salves e vivas, durante a execução de um hino de louvor à beata, o animador vai destacando as virtudes de Nhá Chica e incentivando as pessoas a participarem da campanha de arrecadação de fundos para as obras da ABNC e doações para a manutenção do santuário. Percebe-se que a organização da igreja vale-se de um momento de espiritualidade e faz de um ato de fé na beata Nhá Chica um instante de necessidade capitalista, ao arrecadar fundos para as obras. Este fato nos remete a Marx (1975) ao apontar os princípios sociais do cristianismo, realçando entre eles a necessidade de uma classe dominada e oprimida contribuir para ter, no céu, a recompensa de todas as infâmias sofridas na terra.

Ao comemorar a aprovação da beatificação de Nhá Chica, a igreja católica reforça e divulga, mesmo que indiretamente, o atrativo, exclusivo e diferencial, que Baependi passa a ter de forma oficializada pela maior instância religiosa católica.

Há no município um Mapa Turístico Ilustrado do Patrimônio Histórico e Cultural de Baependi - MG; nele consta uma breve história da cidade, salientando a importância de Nhá Chica para o reconhecimento do município em escala nacional e internacional. Este material tem a logomarca da prefeitura de Baependi e o site oficial do município, juntamente com uma imagem do artesanato da cidade, a casa de cultura, onde funciona a Secretaria de Turismo e imagens de todas as igrejas católicas bem como a história de cada uma.

"O turismo não pode ser apontado como o sujeito desses processos, mas sim, como o resultado das ações e das interações dos diversos agentes sociais que o produzem" (Fratucci, 2007, p. 3). Destaca-se na citação do autor a importância das ações e, principalmente, a interação dos agentes no processo de turistificação; o que pode ser confirmado na elaboração deste mapa, ao associar interesses da igreja e do poder público.

Para a data de beatificação de Nhá Chica, a prefeitura municipal de Baependi em parceria com o governo do estado de Minas Gerais transformou a cidade em uma arena religiosa. A prefeitura juntamente com a câmara de vereadores elaborou e sancionou a Lei 2890/13 (2013), regularizando parcerias e autorizando gastos com o evento da beatificação de Nhá Chica. No local onde a cerimônia foi realizada, uma área de $58.000 \mathrm{~m}^{2}$, foram instalados: uma praça de alimentação, um palco, quatro telões, setores de convidados e imprensa e 4.000 cadeiras distribuídas pelo local para alguns fiéis (Silva, 2013).

De acordo com o jornal Correio do Papagaio, em sua edição online de 21 de fevereiro de 2013, o governo de Minas Gerais em parceria com a prefeitura de Baependi e a igreja católica participaram de uma reunião para traçar os planos para a data da beatificação (“Baependi Se Prepara Para a Beatificação de Nhá Chica”, 2013).

Como visto nessas ações apresentadas, com o objetivo de divulgação dos atrativos turísticos e também no intuito de valorizar o processo de beatificação de Nhá Chica, 
o poder público, como instância de poder, independente da esfera, seja estadual ou municipal, investe no processo de turistificação dos lugares ao realizar obras, valorizando-os. Fratucci (2007) entende o Estado como um agente social que age e interage sincronicamente no acontecer turístico. $\mathrm{O}$ autor parte do entendimento

do agente enquanto fator capaz de produzir um efeito sobre determinado fato ou atividade, podemos afirmar que o agente turístico compõe-se pelas pessoas, grupos ou instituições com poder de gerar um efeito sobre o fenômeno ou sobre a atividade turística, ou seja, com capacidade de intervir, modificar ou influenciar o seu curso. (Fratucci, 2007, p. 3)

Os agentes irão participar da turistificação dos lugares, entendida como um processo, uma condição para o desenvolvimento da atividade turística em um espaço determinado. "A turistificação é a materialização de espaços eleitos para a produção e consumo turísticos" (Taveira, 2015).

A prefeitura de Baependi, entendida como um agente entre os planejadores e promotores territoriais, organizou em 2014 um Mapa Turístico Ilustrado do Patrimônio Histórico e Cultural, que é distribuído gratuitamente no município. Trata-se de um mapa em escala de 2/100 representando o centro da cidade. 0 mapa reúne uma grande variedade de elementos, entre eles, o portal da cidade, a Casa de Cultura, a Praça da Bíblia, o pontilhão do centro, a casa de Nhá Chica e todas as igrejas católicas, estando estas representadas também por fotos. Constam no mapa símbolos iconográficos utilizados pela atividade turística para representar locais de interesse turístico e serviços. 0 mapa indica as saídas da cidade, apontando a direção de outros municípios a leste e ao sul de Baependi e destaca o caminho velho da estrada real que corta a cidade. Telefones úteis estão relacionados no mapa e em vermelho está destacado o quarteirão, nomeado como Nhá Chica, no qual está localizado o santuário de Nossa Senhora da Conceição - Igreja de Nhá Chica. Nota-se claramente a intensão da prefeitura em promover o turismo religioso, mesmo não o citando no mapa, ao divulgar os atrativos religiosos católicos.

As empresas hoteleiras constituem um dos mais importantes elementos essenciais da infraestrutura turística, envolvendo inúmeros negócios complementares à sua atividade, desde a época do surgimento da atividade turística (Beni, 2001; Tuch \& Spolon, 2001). A rede hoteleira, como a de Baependi, colabora no processo de produção do espaço ao transformar a hospedagem em mercadoria em um plano de consumo como estratégia para obtenção de lucro, incluindo geração de empregos, divulgação e comercialização dos atrativos turísticos, envolvimento de outros setores para sustentar a atividade, entre outros. Para Costa (2010), os interesses do capital privado reorganizam os espaços, programando o descanso e o divertimento para a realização do consumo.

A rede hoteleira de Baependi é composta por 13 estabelecimentos, compondo sua "oferta técnica" (Ruschmann, 2008), sendo cinco pousadas, quatro hotéis e quatro hotéis-fazenda; cinco deles existem há menos de 15 anos, ou seja, foram criados após o início do processo de beatificação de Nhá Chica. 
Nota-se em Baependi uma expectativa positiva por parte dos representantes da rede hoteleira, pois, mesmo alegando que a maioria dos turistas não se hospeda no município, a maioria dos entrevistados afirmou ter havido aumento no fluxo de turistas religiosos em seus estabelecimentos. Outro fato a ser destacado diz respeito aos cinco novos hotéis inaugurados nos últimos 15 anos, o último deles, em abril de 2016. Isto demonstra a influência do setor hoteleiro no processo de turistificação do espaço, contribuindo para aumentar a divulgação dos atrativos turísticos de Baependi. Incentivado pelo capital privado, o mercado é, atualmente um dos principais agentes da turistificação, sendo capaz de promover produtos turísticos em variados espaços (Knafou, 2001).

Os agentes envolvidos no processo de turistificação contribuem para a produção da atividade turística e, concomitantemente, para a produção do espaço.As ações por eles implementadas impactam o espaço, contribuindo na tríade dialética, prática espacial, representação do espaço e espaço da representação. Lefebvre (1972/2008) aponta os conceitos estabelecidos como espaço concebido, planejado, uma relação entre os dominantes e o produto. Esta relação resultará no espaço do vivido, do cotidiano, do ir e vir das pessoas, habitantes e usuários deste espaço. Permeando estas relações, como resultado delas, o espaço do percebido nos remete à materialidade desta produção enquanto prática espacial concluindo assim a tríade dialética do autor.

\section{Considerações Finais}

Em uma análise sobre produção do espaço, elaborar uma síntese, remete-nos a um recomeço, afinal, o espaço apresenta-se como movimento do acontecer. Investigar a reprodução do espaço traduz-se em uma tarefa desafiadora, uma vez que trata-se de um objeto de pesquisa vivo, interagindo e sofrendo interações na sua produção, escapando-nos como algo em transformação. 0 espaço apresenta-se dinâmico, não estático, movimentando-se em um devir constante. Ele não existe em sim mesmo e requer que seja produzido social e materialmente alterando seus padrões de uso.

Baependi gentilmente serviu-nos de área para estudos, apresentando a cada ida a campo novas formas para seu processo de reprodução espacial. 0 espaço valoriza-se como mercadoria, consumido em uma relação dialética valor de uso-valor de troca; na qual, ao se atribuir novos usos ao espaço, este valoriza-se e passa a ter novos valores para troca, o que atende aos ideais capitalistas.

Centenas de visitantes chegaram e se foram, trocando experiências, trazendo e levando informações, fornecendo e consumindo do banquete turístico ali estabelecido. Os moradores participaram desta ceia turística, direta ou indiretamente, ao estabelecer, ainda que mínimo, contato com o visitante. Informações foram oferecidas para orientações solicitadas, comércios variados foram realizados e a troca foi estabelecida. A troca é um elemento integrante do modo de produção capitalista, no qual o espaço produz-se e reproduz-se incorporando-a e a reprodução espacial de Baependi insere-se nela, estabelecendo novas relações de produção nas quais tudo é passível de consumo. 
Nessa troca entendemos a participação ativa de dois sujeitos que se complementam e se diferenciam ao mesmo tempo, estabelecendo dessa forma, a dialética entre os moradores e os visitantes. Nesse estudo ficou evidenciada a importância do turista no processo de turistificação dos lugares e seu papel enquanto um dos agentes modificadores do espaço. Esse espaço em questão é justamente o espaço do vivido, do morador local, que ora se beneficia das atividades turísticas e ora não, estabelecendo dessa forma contradições.

As contradições surgem exatamente no momento em que a produção não atende a todos os envolvidos, uma vez que os interesses não são unânimes. Ou de outra maneira, quando a produção do espaço dá-se no desencontro entre temporalidades e espacialidades, no qual cada prática social tem sua organização, podendo justamente traduzir-se em negação do real.

Em Baependi, nota-se uma convivência pacífica e as maiores reclamações partem da comunidade local que gostaria de ter maior envolvimento com a atividade turística e dela obter mais lucros, atribuindo ao poder público a falta de organização que resulta em um aproveitamento não satisfatório.

O trabalho de campo evidenciou a importância de moradores e turistas nessa produção espacial e deixa transparecer a relação dialética entre os mesmos, uma vez que a produção do espaço é uma relação social e, desta forma, articula interesses diversos envolvendo contradições da realidade.

\section{Referências}

Andrade, J. V. (2000). Turismo: Fundamentos e dimensões. Ática.

Baependi se prepara para a beatificação de Nhá Chica. (2013, 21 de fevereiro). Correio do Papagaio. http://www.correiodopapagaio.com.br/baependi/noticias/baependi_se_prepara_para_a_beatificacao_de_nha_chica

Beni, M. C. (2001). Análise estrutural do turismo. Senac.

Caldeira, A. B. (2014). Cultura e turismo. In R. C. Aranha \& A. J. T. Guerra (Eds.), Geografia aplicada ao turismo (p. 147). Oficina de textos.

Cooper, C., Fletcher, J., Wanhill, S., Gilbert, D., \& Shepherd, R. (2001). Turismo: Princípios e prática (R. C. Costa, Trad.). Bookman. (Trabalho original publicado em 1998)

Costa, C. L. (2010). Cultura, religiosidade e comércio na cidade: A festa em louvor à Nossa Senhora do Rosário em Catalão - Goiás [Tese de doutoramento, Universidade de São Paulo]. Biblioteca Digital USP. https://www.teses.usp.br/teses/disponiveis/8/8136/tde-06122010-151424/pt-br.php

Cruz, R. de C. A. da. (2003). Introdução à geografia do turismo. Roca.

Cruz, R. de C. A. da. (2007). Geografias do turismo: De lugares a pseudo-lugares. Roca.

Fratucci, A. C. (2007). Os processos de turistificação do espaço e atuação dos seus agentes produtores. In X ENTBL, João Pessoa - PB. http://www.academia.edu/869796/0s_processos_de_ turistifica\%C3\%A7\%C3\%A3o_do_espa\%C3\%A70_ea_atua\%C3\%A7\%C3\%A3o_dos_seus_agentes_ produtores 
Gottdiener, M. (2010). A produção social do espaço urbano (G. G. de Souza, Trad.). Edusp. (Trabalho original publicado em 1993)

História. (s.d.). A origem de Nhá Chica. http://aorigemdenhachica.blogspot.com/p/historia.html

Instituto Brasileiro de Geografia e Estatística.(s.d). Baependi. Retirado a 1 de outubro, 2021, de https:// cidades.ibge.gov.br/brasil/mg/baependi/panorama

Knafou, R. (2001). Turismo e território: Por uma abordagem científica do turismo. In A. B. R. Rodrigues (Ed.), Turismo e geografia: Reflexões teóricas e enfoques regionais (pp. 62-74). Hucitec.

Lefebvre, H. (2006). A produção do espaço (D. B. Pereira \& S. Martins, Trad.). Éditions Anthropos. (TrabaIho original publicado em 2000)

Lefebvre, H. (2008). Espaço e política (M. M. de Andrade \& S. Martins, Trad.). UFMG. (Trabalho original publicado em 1972)

Lefort, M. J. P. (1992). Francisca de Baependi. Campanha.

Lei 2890/13, de 22 de abril de 2013. (2013).

Marx, K. (1975). Textos filosóficos (M. F. M. Simões, Trad.). Editorial Estampa.

Palazzolo, P. F. J. de. (1973). Nhá Chica: A pérola escondida. Ed. Baipendi.

Ruschmann, D. (2008). Turismo e planejamento sustentável: A proteção do meio ambiente. Papirus.

Sacramento, J. A. de Á. (2006). Nhá Chica, a santa do rio das mortes. Revista da Academia de Letras de São João del Rei, (411), 141-161.

Seda, R. E. (2013). Nhá Chica: Mãe dos pobres. Editora ComDeus.

Silva, S. (2013, 25 de dezembro). 'Vamos manter a esperança', diz bispo sobre canonização de beata. Globo. http://g1.globo.com/mg/sul-de-minas/noticia/2013/12/vamos-manter-esperanca-diz-dom-sobre-canonizacao-de-nha-chica.html

Souza, M. L. (2002). Como pode o turismo contribuir para o desenvolvimento local? In A. B. Rodrigues (Ed.), Turismo e desenvolvimento local (pp. 91-103). HUCITEC.

Taveira, M. da S. (2015). A turistificação de São Miguel do Gostoso: A internacionalização da "Cidade dos Ventos". Revista Turydes: Turismo y Desarrollo, (19). http://www.eumed.net/rev/turydes/19/paisagem. html

Tuch, D. L., \& Spolon, A. P. G. (2001). Planejamento hoteleiro. In M. G. dos R. Ansarah (Ed.), Turismo: Como aprender, como ensinar (pp. 353-374). Senac. 